\title{
Reasonable, Adequate and Efficient Allocation of Liability Costs for Automated Vehicles: A Case Study of the German Liability and Insurance Framework
}

\author{
Fabian PÜTZ, Finbarr MURPHY, Martin MULLINS, Karl MAIER, Raymond FRIEL \\ and Torsten ROHLFS*
}

\begin{abstract}
In general, a functioning liability and insurance framework should ensure an adequate level of third party claimant protection and a reasonable and adequate final allocation of liability costs for the involved parties. This research examines whether the liability and insurance framework resulting from the amendment to German Road Traffic Act meets these two central objectives. The article shows that a reasonable and adequate allocation of liability costs is inhibited because of several barriers that hinder the shift of liability costs from the owner of the vehicle to the manufacturer. In particular, it is highly dependent on the practical application of subrogation claims. The ability and the motivation of motor insurers to conduct subrogation claims could be negatively affected because of a lack of required technical and engineering know-how and because a market-wide conduction of subrogation claims would erode the business model of motor insurance. This article proposes changes to the current framework particularly by removing specific exclusions of product liability and by easing the burden of proof of a product defect.
\end{abstract}

\section{INTRODUCTION}

The progressive technical development in the field of advanced driving assistance systems (ADAS) and automated driving makes it feasible that motor vehicles with a high level of automation will be ready for market within the next decade. The vision of automated vehicles on public roads not only depends on technical progress but also requires an adequate liability framework to ensure legal certainty for the relevant stakeholders on both the demand and supply side.

Several national legislators have recognised the need for adjustments and are currently discussing amendments to existing liability laws (eg see draft law amendment in the $\mathrm{UK}^{1}$ ). The German legislative body has already implemented an amendment to the existing Road

\footnotetext{
* Fabian Pütz, Finbarr Murhphy, Martin Mullins and Raymond Friel are members of the Emerging Risk Research Group at University of Limerick. Karl Maier and Torsten Rohls are Professors at the Institute of Insurance Management at Technische Hochschule Köln.

1 L Butcher, L Conway and T Edmonds, Briefing Paper: Vehicle Technology and Aviation Bill 2016-17 (London, House of Commons Library 2017).
} 
Traffic Act (Straßenverkehrsgesetz (StVG)). This amendment sets legal requirements for the operation of highly and fully automated vehicles ${ }^{2}$ and mainly preserves the existing liability and insurance framework, characterised by a combination of strict liability of the vehicle owner ${ }^{3}$ and fault-based liability of the (human) driver. This liability framework is coupled with obligatory insurance to be maintained by the owner, covering liability costs of himself, the driver and the titleholder of the respective vehicle. Original equipment manufacturers (OEMs) are not directly included into the legal framework and the legislator expects that motor insurance companies will examine and conduct subrogation claims under existing product liability law in the case that a defect of the automated driving system causes an accident.

In general, a functioning liability and insurance framework should meet two central objectives. In the external relationship to the damaged third party, the design of the framework has to ensure an adequate level of claimant protection. In the internal relationship between the liable parties, a reasonable and adequate ultimate allocation of liability costs fulfils an important incentive function for the involved parties. On a more abstract level, the retrospective allocation of liability costs also has a preventive function, aiming to achieve a balance between the level of independent and free individual action and the level of reasonable caution and care when exposing risks to the society. ${ }^{4}$

Because the progressive automation of motor vehicles will successively reduce the relevance of the owner and human driver for the occurrence of road accidents, we use the liability and insurance framework resulting from the amendment to the StVG in Germany as a case study to analyse whether this framework adequately ensures these two central objectives.

This issue has already been subject to existing academic research. With regard to the inherent level of claimant protection, the prevailing opinion recognises the adequacy of the existing framework and consequently seeks to preserve the current approach. ${ }^{5}$ Referring to the adequate allocation of liability costs, Lohmann recognises the importance of the incentive function of liability cost allocation and concludes that liability costs would be fairly balanced between the owner and manufacturer of the vehicle by the way of subrogation claims. ${ }^{6}$ That this assumption could be too optimistic and not hold true in the application of current product liability law is only slightly touched on by Vellinga. ${ }^{7}$ By contrast, Armbrüster states that the question about the

\footnotetext{
2 The German legislative body does not follow the classification wording of SAE but uses the terminology of the German Federal Highway Research Institute. The equivalent levels of automation referring to SAE nomenclature would be conditional automation (level 3) and high automation (level 4).

3 We use the term "owner" for the German legal term "Fahrzeughalter" and the term titleholder for the German legal term "Fahrzeugbesitzer". German law distinguishes between the right of property title and the right of disposal. The owner of a vehicle is the person who owns the right of disposal and has the duty to maintain the vehicle in safe condition. The titleholder is the person or institution formally owning the property title of the vehicle.

4 See S Shavell, "Liability for Accidents" (2007) 1(2) Handbook of Law and Economics 142 or MG Faure, "Liability for Unknown Risks: A Law and Economics Perspective" (2016) 7(2) Journal of European Tort Law 198-228.

5 M Schubert, "Autonomous Cars-Initial Thoughts About Reforming the Liability Regime" (Gen Re: Insurance Issues, May 2015) at p 3 <www.genre.com/knowledge/publications/iipc1505-en.html > accessed 14 June 2018; U Lange, "Automatisiertes und autonomes Fahren - eine verkehrs-, wirtschafts- und rechtspolitische Einordnung" (2017) NZV 345; see also notes 6 and 7 below.

6 M Lohmann, "Liability Issues Concerning Self-Driving Vehicles" (2016) EJRR 335 at 339.

7 N Vellinga, "From the testing to the deployment of self-driving cars: Legal challenges to policymakers on the road ahead" (2017) Computer Law \& Security Review 847 at 860.
} 
allocation of liability costs practically would only be of minor relevance. This is because liability costs would flow back to the owner of the vehicle anyway, either by paying the insurance premium or an additional price component when purchasing the vehicle. ${ }^{8}$

With regard to these positions, we suggest a more granular analysis of the existing liability and insurance framework. This is necessary to show that a reasonable and adequate ultimate allocation of liability costs is indeed also of practical importance, as it determines whether insurance premiums could shift from motor insurance to product liability insurance. Based on this assumption, an in-depth analysis of single provisions and the interrelations of the different sources of law is applied, as only this makes it possible to deduce whether the existing framework actually leads to a reasonable allocation of liability costs.

With this approach, we also find that the existing liability and insurance framework broadly matches the predominant goal of an adequate protection of injured claimants. However, we show that the high level of claimant protection could be interrupted in large scale accident events.

Assessing the framework's ability to reasonably allocate liability costs, we find that there are specific exclusions and limitations of liability in the Product Liability Act as well as shortfalls in terms of the ability of motor insurers to conduct subrogation claims against a manufacturer. In addition, we also find a lacking interest of motor insurers to conduct subrogation claims as this successively erodes the own business model.

Ultimately, this could impede a reasonable and adequate ultimate allocation of liability costs, which potentially inhibits the crucial incentive function of liability.

\section{Current law Regarding legal liability fOR AUtomated Vehicles}

Due to the progressing automated driving capability of motor vehicles, the German legislative body has recognised the need for adjustments to the StVG. Therefore, an amendment was elaborated which came into force in June $2017 .^{9}$ The aim of this amendment is to ensure a clear allocation of liability for highly and fully automated vehicles (SAE level 3 and 4). Autonomous ${ }^{10}$ vehicles are not yet within the scope of this amendment.

In general, the StVG distinguishes between two parties, which can be addressed when a third party suffers a damage due to the operation of a motor vehicle. While the StVG imposes strict liability on the owner of a vehicle ( $\$ 7 \mathrm{StVG})$, the human driver is only liable based on fault ( $\$ 18 \mathrm{StVG}$ ). This legal approach is coupled with the obligation for the owner to take out and maintain motor third party liability (MTPL) insurance coverage protecting himself, the titleholder and the driver of the vehicle against liability claims from third parties caused by the use of the vehicle ( $\$ 1$ Law on compulsory insurance for owner s of motor vehicles (PflVG)). In this respect, the damaged third party has the possibility to directly claim against the respective MTPL insurer (§ 115 Insurance contract law (VVG)).

8 C Armbrüster, “Automatisiertes Fahren - Paradigmenwechsel im Straßenverkehrsrecht?” (2017) ZRP 5.

9 Achtes Gesetz zur Änderung des Straßenverkehrsgesetzes vom 16. Juni 2017 (Bundesgesetzblatt Jahrgang 2017 Teil I Nr. 38 Seite 1648).

10 We use the term "autonomous" vehicle for vehicles which technically have the capability to self-reliantly fulfil the driving task in a comprehensive manner and do not require a (human) driver at all (SAE level 5). 


\section{Liability of the owner of the motor vehicle}

The strict liability approach of the German liability system is based on the legal logic that the usage of a motor vehicle opens an (abstract) source of risk to society. This introduction of risk is legally accepted, but the individual who benefits from the usage of the risky object has to bear strict liability if the (abstract) risk becomes manifest. As well as owners of motor vehicles, the concept of strict liability is inter alia applied to owners of aircraft, animals and operators of railways and power plants.

The owner does not necessarily need to be the titleholder of the vehicle, as German law separates the right of property title determining the titleholder ( $\$ 903$ German Civil Code (BGB)) and the right of possession determining the owner (§854 BGB). ${ }^{11}$ The main characteristics of the owner are that he is the person who uses the vehicle for his own account and has the power of disposition. The owner regularly bears the operating costs and benefits from the use of the respective motor vehicle. ${ }^{12}$

The owner is obliged to compensate for claims with strict liability (§ 7(1) StVG). To ensure the ability to meet these financial obligations, the owner has to maintain obligatory MTPL insurance coverage ( $\$ 1$ PflVG). The strict liability of the owner for losses due to the same event is generally limited to $€ 5$ million for personal injury and death of a third party and to $€ 1$ million for property losses (§ 12(1) StVG). However, these maximum liability limits are doubled if the damages result from the use of a highly or fully automated driving function (§ 12(1) StVG).

The obligation of the owner to bear strict liability is only excluded where the accident is caused by force majeure ( $\$ 7(2) \mathrm{StVG})$ or if the driver used the vehicle without the knowledge and will of the owner, unless the use of the vehicle has been made possible by fault of the owner (§ 7(3) StVG). In addition, the obligation to compensate a damaged party is excluded, if the injured party was actively engaged in the operation of the motor vehicle ( $\$ 8$ no $2 \mathrm{StVG}$ ). With this exclusion, the liability of the owner for damages to the driver is regularly exempted. Assessing this exclusion against the background of automated driving vehicles, it is questionable, whether the (human) driver can still be classified as actively engaged in the operation of the motor vehicle. Because of the legal approach to ascribing the human (driver) the attribute of being the driver even while using automated driving functions in the scope of the intended use, it could be assumed that this exclusion will still be applicable to automated vehicles. This is because the driver is still in a position of latent engagement due to the obligation of an adequate level of awareness and supervision even if he does not actually fulfil the active steering task during automated mode. ${ }^{13}$ However, with autonomous vehicles this exclusion should logically be void if no passenger in the vehicle can be considered to be (actively) engaged in the operation of the vehicle anymore.

\footnotetext{
11 For example, in case of a credit-financed car the bank typically is the titleholder of the car as long as the debtor has not paid back the credit. However, the debtor still has the factual right of daily disposition and the duty to adequately maintain the vehicle as the owner of the vehicle.

12 D Euler and A Kreuter-Lange, "Kraftfahrzeughaftpflichtversicherung" in W Halm, A Engelbrecht and F Krahe (eds), Versicherungsrecht-Handbuch des Fachanwalts (4th edn, Cologne 2011) at 1716.

13 B von Bodungen and M Hoffmann, “Autonomes Fahren - Haftungsverschiebung entlang der Supply Chain? (Teil 1)" (2016) NZV 449.
} 


\section{Liability of the driver of the motor vehicle}

According to the StVG, the driver of a vehicle is liable up to equal compensation limits as the owner, if the damage to a third party is due to his fault. For this, the fault of the driver is presumed ( $\S 18 \mathrm{StVG}$ ) but can be refuted by providing evidence.

In the amendment of the StVG, the definition of the "vehicle driver" is not extended to the automated system but designates the human driver as the driver of the vehicle even for the time he does not technically control the vehicle by an active steering action $(\S 1 \mathrm{a}(4) \mathrm{StVG})$. Within the scope of the intended use of the automated driving function, the driver of the vehicle is generally allowed to turn away from the traffic scene and vehicle control ( $(1 b(1)$ StVG) but has to keep situational awareness to always fulfil his obligation to immediately (without undue delay) take over vehicle control

- if the highly or fully automated system so requests or ( $\$ 1 b(2)$ no $1 \mathrm{StVG})$;

- if he recognises or should recognise on the basis of obvious circumstances that the conditions for the intended use of the highly or fully automated driving functions no longer exist (\$1b(2) no $2 \mathrm{StVG})$.

Even if the amendment to the StVG does not explicitly differentiate between highly and fully automated vehicles, the legal requirements of the driver of the vehicle implicitly lead to a certain distinction. This is because not only the scope of the intended use but also the duration and extent of (legally accepted) turning away from the driving scene should increase with progressing automation.

In addition, the driver is also liable under the general provisions of the German Civil Code, if he intentionally or negligently unlawfully injures the life, body, health, freedom, property or another right of another person ( $\$ 823(1)$ BGB). The conditions of an intentional injury are that the damaging party acts consciously and willingly with regard to the occurrence of the damaging event. A person's act is classified as being negligent if the person fails to exercise reasonable care (§ 276(2) BGB).

In contrast to the provisions of the StVG, the liability resulting from the BGB is not limited to a maximum amount. However, the damaged third party bears the burden of proof that the preconditions of liability (intentional or negligent, unlawful action) and the causality between the action and the damage are met.

\section{Product liability}

The vehicle producer is not explicitly included in the liability framework of the StVG. However, even if the car manufacturer is not explicitly mentioned as a liable person, the explanatory memorandum clarifies that the respective motor insurance company has the possibility to subrogate claims under applicable product liability laws.

As the provisions regarding product liability resulting from Directive 85/374/EEC are largely harmonised in the European Union, the following analysis focuses on the specific German implementation of these provisions in the Product Liability Act (ProdHG), acknowledging that producer liability can also result from either a contractual relationship or tortious claims under the German Civil Code.

The provisions of product liability hold a producer liable for claims of a damaged third party if a defective product causes a person's death, bodily injury, damage to his health 
or damage to an item of property ( $§ 1(1)$ ProdHG). The liability resulting from ProdHG is strict.

The scope of the ProdHG only covers property damage if this damage was caused to an item of property other than the defective product (ibid). Following from this, the scope of the ProdHG does not cover spreading defects which are defects to a functionally separable component part that lead to a damage of the whole product. Hence, subrogation claims for damages to property items are only possible for MTPL insurance losses and not for insured losses to the own vehicle.

Furthermore, the producer has only to compensate for damages if the item of property is of a type which is ordinarily intended for private use or consumption and mainly used accordingly by the damaged person (ibid). This exclusion is especially relevant for third party damages to commercially or publicly used property/infrastructure, such as commercial vehicles (buses, commercial trucks), buildings or traffic infrastructure, which are not covered by the literal interpretation of this provision. Assessing the wording of this legislation in the case of a car-to-car-accident event, vehicles mainly used for a commercial purpose would generally not be covered by the scope of the ProdHG. Today, the prevailing possession-based mobility approach highly reduces the relevance of this exclusion. Assuming that the progressive automation will promote a shift towards the usage of commercial shared-mobility services, the relevance of this exclusion could potentially grow in the future. Assuming this, it is questionable whether this exclusion is reasonable, because the commercial usage of shared passenger vehicles, except for the frequency of usage, does usually not materially differ from the characteristics of private usage. In addition, most companies that use vehicles for a commercial purpose generally do not have specific technical and engineering know-how before purchasing (automated) vehicles and therefore depend on the reliability of vehicles in the same way as private users do.

The ProdHG defines a product as defective when it does not provide the safety that the consumer, with consideration of all circumstances, is entitled to expect. Relevant circumstances which have to be considered are the presentation of the product, the kind of use that has reasonably to be expected and the time the product was put into circulation ( $\$ 3$ ProdHG). For the legal interpretation of the existence of a defect, the objective safety expectations of a reasonable average user or consumer are used as a reference. The damaged party bears the burden to prove the defect, the damage and the causal relationship between the defect and damage (§ 1(4) ProdHG). As an easing of the burden of proof, the damaged party only has to prove that the defect existed at the time of the loss occurrence but not the temporal and local origin of the defect. ${ }^{14}$ If the damaged party can provide this evidence, the manufacturer has to prove that exclusions of liability are applicable.

In contrast to the provisions of the StVG, the ProdHG does not generally limit the maximum liability amount for damages caused to an item of property. However, the maximum liability amount for personal injury damages caused by identical products with the same defect is limited to $€ 85$ million ( $\S 10$ ProdHG). The application of this maximum liability amount is not harmonised within the European Union but if a member

14 A Komescher, "Produkthaftung" in Halm, Engelbrecht and Krahe, above, n 12, 2229 ff. 
state decides to implement a different liability limit, the minimum threshold of €70 million has to be applied. ${ }^{15}$ Even if we assume that this limit is high enough to cover losses arising from single accident events, this limitation of liability could especially gain in relevance, because the interconnection of vehicles and the correlation of risk behaviour of a vehicle fleet based on the same algorithm potentially induces accumulation risk, where multiple accidents could cause personal injury damages in excess of the implemented threshold. In this case, it would be unreasonable if exceeding loss amounts were to shift back to either the insured owner or the damaged third party.

Furthermore, the obligation to compensate for property damage under the ProdHG only applies if the respective damage exceeds a threshold of $€ 500$ ( $\$ 11$ ProdHG). Hence, motor insurers could not subrogate property losses that do not exceed this threshold. Under current regulations, this is understandable as legal and procedural costs induced by conducting of subrogation claims could easily exceed this threshold and lead to economic inefficiencies. We expect that this threshold should not lead to a material inadequate allocation of liability costs from a macro-level view on the overall insured portfolio, as MTPL losses below this threshold account for only $0.43 \%(2015)^{16}$ of all insured MTPL loss expenditure. However, from the perspective of the individual insured person, not being able to conduct a subrogation claim because of the minimum threshold can have adverse consequences because of the impact to the individual insurance premium, which is commonly based on a no-claims bonus system in the German market.

In addition to the limitation of maximum liability amounts for personal damages and the deductible for property damages, the liability of the manufacturer inter alia is generally excluded if, considering all the circumstances, it is probable that the defect which caused the damage did not exist at the time when the producer put the product into circulation (Article 1(2) no 2 ProdHG).

This exclusion is relevant as the capability of automated vehicles will likely not be static but could be altered by (over-the-air) software updates so that the inherent accident risk exposure fluctuates over time. However, the provisions of the ProdHG generally do not oblige the producer to monitor the circulated product after sale. Therefore, it should be discussed whether the temporal attachment point of putting the product into circulation has to be renewed with every (material) change to the product functionality. On a technical side, this discussion has also to be supported by vehicle approval authorities with setting guidelines defining material changes to the system functionality, which require a repeat process of type approval test. If the temporal attachment point of product circulation would not be renewed with every (material) change, residual technological development risk would fall back to the owner of the vehicle, who is liable with strict liability.

In addition, the legal provision that claims based on the ProdHG expire ten years from the time when the producer put into circulation the product which caused the damage (Article 13 ProdHG) could also lead to a shift of residual technological risk to the owner

15 Council Directive of 25 July 1985 on the approximation of the laws, regulation and administrative provisions of the Member States concerning liability for defective products (85/374/EEC), Art 16.

16 Share of loss expenditures for MTPL-losses, which do not exceed the threshold of $€ 500$, from total loss expenditures for MTPL-insurance in the year 2015. Source: German Insurance Association. 
of the vehicle. This exclusion will not be relevant in the first years with automated vehicles on the road but would apply where an automated vehicle which is more than ten years old causes an accident.

Finally, the liability of the manufacturer is excluded if the state of scientific and technical knowledge at the time when the producer put the product into circulation was not such as to enable the detection of the defect (Article 1(2) no 5 ProdHG). To apply this exclusion of liability it has to be objectively referenced against the scientific and technical knowledge which was generally accepted and available at this time. This exclusion is potentially important with the progressing automation of modern vehicles, because general standards and sufficient case law decisions for programming driving algorithms and testing autonomous vehicles do not yet exist.

\section{AdeQUACY OF THE EXISTING LIABILITY AND INSURANCE FRAMEWORK FOR}

\section{AUTONOMOUS VEHICLES}

Based on the description of the different sources of liability of the owner and driver of a motor vehicle on the one hand and the producer on the other, the resulting liability and insurance framework is depicted in Figure 1.

Even if a claim of a damaged third party against the producer is legally possible, the broken line reflects the associated higher financial and organisational effort required. Hence, the damaged third party will rather not use this path if the claim is sufficiently compensated by a direct claim against the motor insurer due to strict liability of the owner.

Today, over $90 \%$ of all road accidents are caused by human error. Therefore, an investigation of product liability claims is very low in the (German) motor insurance market. However, with the progressive automation of motor vehicles and a shifting responsibility for the causation of accidents to OEMs and their suppliers, the interdependencies of the current liability and insurance framework and regulations regarding product liability have to be assessed and aligned to create a consistent and adequate framework for automated vehicles.



Figure 1. German liability and insurance framework for losses caused by (highly and fully automated) motor vehicles. The figure depicts an overview of the several sources of liability of the involved parties in case of losses due to road accidents. 
In the following, we analyse the adequacy of the existing liability and insurance framework for automated and autonomous vehicles based on the following criteria of assessment:

- Protection of the claimant: Does the current framework adequately ensure the protection of the damaged (third party) claimant?

- Responsibility-based allocation of costs: Does the current framework adequately allocate liability costs to the responsible party?

- Cost-efficiency of the claims process: Does the current framework ensure a costefficient allocation of liability costs?

Within this analysis, we make suggestions for adjustments to the liability and insurance framework that would ensure higher adequacy for the categories analysed.

\section{Protection of the claimant}

The central idea of the existing (strict) liability and insurance framework is to ensure an as high as practicably possible level of protection for the damaged third party claimant. Claimant protection must be evaluated as a two-stage process considering the maximum extent of (financial) protection and the required processual effort to achieve this compensation. Hence, the following analysis assesses the easiness of the claims process (eg regarding the speed of the process, clarity of relevant institutions to contact and the burden of proof) and the material (maximum) compensation to the claimant.

The central idea of claimant protection from a processual point of view is anchored with the strict liability of the vehicle owner, obligatory MTPL insurance and the possibility to claim directly against the respective motor insurer. The strict liability of the owner and the possibility to claim directly against the motor insurance company is a generally proven process that ensures a clear path for compensation from the motor insurer as the central institution, which comprehensively compensates justified liability claims for all probably liable parties. In fact, this strict liability approach is also practicable with automated vehicles, so that it can serve as a blueprint for other countries' legal approaches, which are based on fault of the human driver. ${ }^{17}$ That said, the strict liability approach has to be embedded into a well-functioning and robust insurance market to effectively protect third party claimants.

The preservation of the current process for automated vehicles in large part will assure a claimant-friendly processing of liability claims with respect to the speed of the process and clarity about the relevant institutions. This is supported by legislation, which generally limits the period for processing claims to three months ( $\$ 3$ a PflVG). Therefore, a speedy processing of third party claims is supported by the legal environment. However, the adequacy of the current framework for autonomous vehicles will only guarantee a high level of claimant protection if the maximum material compensation covered by this process is also adequately determined.

17 S Duffy and J Hopkins, "Sit, Stay, Drive: The Future of Autonomous Car Liability" (2016) SMU Sci \& Tech Law Rev 101 at 116. 
On the one hand, it could be argued that the current framework generally does not reduce the compensation of a claimant damaged by an automated vehicle. This is because the doubling of the maximum liability limits for owner's strict liability increases the maximum achievable compensation that can be claimed without providing evidence of fault. The legislator inter alia rationalises the need for an increase, because the fault-based unlimited liability of the (human) driver may not apply where the accident is caused by a technical failure of the automated driving function.

That said, it is questionable whether the increase of maximum liability amounts will adequately replace the unlimited fault-based liability of the (human) driver and adequately ensure the protection of the claimant for severe loss scenarios. This is because the current approach of applying the liability of the owner and (human) driver, which are covered by motor insurance, on a first level and the possibility to subrogate claims under product liability law only on a second level procedurally separates the damaged third party from claims against the manufacturer. This separation could turn out to be disadvantageous if the claimant is only compensated up to the lower limitations of strict liability of the owner, even if the manufacturer is held liable during the subrogation claim process of the motor insurer.

With a limited financial tail-risk of single insured MTPL losses on a portfolio basis, we expect that the great majority of accidents will be sufficiently covered by the increased maximum liability amounts. However, single accident occurrences have already shown that possible maximum losses for MTPL insurance can greatly exceed the applicable threshold. For instance, this can be illustrated by the highest recorded MTPL insurance loss, where due to the fault of the driver, a vehicle crashed with a train, which derailed and crashed into another train. Ten people died and about 80 were injured leading to an insured loss of about $€ 30$ million.

If this accident had been caused by an automated vehicle, the claimant would (additionally) have to claim against the manufacturer under applicable product liability laws for losses, which exceed the maximum compensation amounts of the StVG. This would expose the claimant to higher legal costs and effort. In turn, this potentially hinders claimants from claiming for compensation that exceeds the maximum liability limits of the StVG, even if those claims would be legally justified. In doing so, the current framework could contravene the principle of a one-stop-shop approach and hence reduce the level of claimant protection with regard to the required processual effort to claim for adequate material indemnification.

Therefore, policy sets may be improved by a further increase of maximum liability amounts for owner's strict liability. This approach is also imperative from a societal point of view, because the limitation of maximum liability amounts would otherwise potentially result in disproportionate residual legal risk and uncertainty of compensation to damaged third parties. From an insurance market point of view, this should not be problematic, as commonly sums insured in the German market greatly exceed the liability limits of the StVG anyway. ${ }^{18}$

18 Commonly sums insured in the German motor insurance market are limited to $€ 100$ million. 


\section{Responsibility-based allocation of liability costs}

With automated vehicles on the road, the responsibility for the causation of road accidents will successively shift from the human driver to the automated system itself. Therefore, only accidents that are caused by inadequate maintenance (eg missed software-updates) of the automated vehicle can be attributed to the owner's sphere of responsibility. ${ }^{19}$ With autonomous vehicles, which do not need a human driver anymore, fault of the human driver will no longer be a relevant contributing factor to accident occurrences. The owner of the vehicle will only be left with the possibility to influence the risk of the vehicle through a reasonable effort to maintain the physical components of the vehicle and update the autonomous system's software. Hence, it is expected that the share of accidents which potentially fall under the applicability of product liability will increase. ${ }^{20}$

That said, the preservation of the strict liability approach for automated vehicles is systemically consistent with the legal logic that the owner of the vehicle, from whose use the owner benefits, opens a source of risk to society. Hence, the owner of the vehicle will ultimately bear the residual risk of liability, which legally cannot be attributed to the manufacturer or other potentially liable parties. However, the owner's only limited possibility to influence the risk exposure of the vehicle makes it necessary to reconsider the balance of liability cost allocation between the owner and manufacturer of the vehicle in favour of the owner.

From a macro-level view, which does not consider the allocation of liability costs after a specific insured loss event, it could be argued that the owner of the vehicle will ultimately carry liability costs anyway, either directly by paying insurance premiums or indirectly through an additional price component when purchasing a vehicle. This price component then accounts for the product liability risk of the manufacturer. ${ }^{21}$ However, this argument only ensures that liability costs are adequately attributed to a superordinate entire portfolio (eg homogenous portfolio of insured or portfolio of buyers of certain vehicles) but not that liability costs are also adequately allocated on an individual basis (eg impact on no-claims discount on individual insurance contract).

Furthermore, this perspective does not consider the allocation of expense inflation risk to the owner or manufacturer. Where the owner pays an additional premium when purchasing the vehicle, the risk that the premiums are not sufficient to meet liability claims is shifted to the OEM. By contrast, if the owner of the vehicle is still obliged to pay obligatory motor insurance premiums, the risk of expense inflation indirectly remains with the owner of the vehicle, as it iteratively flows back via insurance premium adjustments. In addition, allocating liability costs to the producer, who adds these costs as an additional premium to the vehicle price, would ceteris paribus mean that less reliable vehicles are in turn more expensive, which in turn reduces the marketability of unreliable vehicles. In this way, the allocation of liability costs to the producer would support a more prudent testing approach of manufacturers before placing their vehicles on the market. ${ }^{22}$

\footnotetext{
19 A Bertolini et al, "On Robots and Insurance” (2016) 8 International Journal of Social Robotics 381 at 385.

20 Bericht der Ethik-Kommission automatisiertes und vernetztes Fahren (Juni 2017) at p 11.

21 See supra, note 8.

22 GE Marchant and RA Lindor, "The Coming Collision Between Autonomous Vehicles and the Liability System" (2012) 52 Santa Clara Law Review 1321 at 1337.
} 
It could further be argued that a responsibility-based allocation of liability costs for a specific accident event is generally applied by the current framework, because the motor insurer covering owner's strict liability in the external relationship to the damaged third party can regress claims from the producer under applicable product liability laws. Where this subrogation claim is successful, the liability costs are ultimately born by the producer. In doing so, the design of the liability and insurance framework has to ensure that the residual risk of owner's liability is not inadequately increased by the design and conditions of the subrogation claim process. For this, the extent of reasonable and adequate allocation of liability costs depends on the willingness and the ability of the motor insurer to conduct subrogation claims under the current product liability laws.

The current scope of MTPL insurance is only limited to the satisfaction of justified claims and the rejection of unjustified claims ("passive legal protection", see $\S 2(1)$ Regulation on insurance cover in motor vehicle liability insurance (KfzPflVV)). In contrast, MTPL insurance does not cover the owner's interest in law enforcement against other parties ("active legal protection"). If a motor insurer settles a justified MTPL claim and the insured is entitled to reclaim damages from another third party, the claim of the insured is assigned to the motor insurer to the extent that the motor insurer already compensated the third party claimant ("cession of right", see $\S 86 \mathrm{VVG}$ ). Hence, the insured currently has neither a legal nor contractual right within the applicable law ( $\$ 2$ (1) KfzPflVV) and standard motor insurance wording that would oblige the insurer to conduct a subrogation claim against the vehicle producer or automotive supplier. This is not problematic for manually driven vehicles because subrogation claims to third parties do not play a significant role and do not affect the overall achievable premium volume of the motor insurance market. Thus, conducting subrogation claims against third parties is in the best (economic) interest of both the insured and motor insurer, as this prevents adverse impacts to the individual insurance contract of the insured and also lowers claims expenses and, in turn, improves underwriting results of the insurer.

This alignment of interest could decrease because the increasing relevance of subrogation claims successively erodes the presence of insurance risk, which is a crucial precondition of the motor insurance business model. Given the market-wide importance of motor insurance business volume, this potential conflict of interest is especially relevant where a motor insurance company has not proactively initiated a structural change to reduce the dependency on contribution margins from MTPL insurance for the financing of companies' overhead costs. Hence, assuming that a progressive shift of liability costs on a superordinate portfolio or market level decreases the overall achievable premium volume, the motor insurer may be less likely to conduct subrogation claims. To ensure a reasonable and adequate allocation of liability costs, we propose an expansion of the obligation of a motor insurance company to conduct subrogation claims in favour of the insured party. However, this would augment the scope of MTPL insurance with a certain degree of active legal protection.

In addition to the willingness of the insurer to conduct subrogation claims, the ability of an insurer to do so depends on the legal and technical know-how and the availability of relevant (telematics) data. These resources are required to be able to provide evidence that the conditions of product liability are met. The burden of proving the presence of a product defect could be difficult, especially for accidents caused by software failure of an 
automated vehicle. This problem is increased by the current limited technical and engineering know-how, which is required and therefore maintained by insurance companies to underwrite retail motor insurance business today. This could lead to the outcome that a subrogation claim against an OEM is not conducted due to a lack of technical expertise and the unknown probability of success. This, in turn, could lead to an inadequate allocation of liability costs at the expense of the insured owner of the vehicle.

Furthermore, the possibility of the motor insurer conducting subrogation claims against the manufacturer of the vehicle is also limited, if the potential exclusions of product liability described in section II.3 are applicable. This especially holds true for damages to own vehicles, which are generally not covered by the provisions of the ProdHG.

\section{Cost-efficiency of the claims process}

Regardless of the question of the current framework's ability to allocate liability costs for accidents in a responsibility-based manner, the owner of the vehicle and even producers are indirectly exposed to adverse economic consequences if the process of allocating liability is not structured efficiently and unnecessarily causes additional processual and legal costs.

Generally, the combination of strict liability with mandatory MTPL insurance and the opportunity to claim directly against the motor insurer is appropriate to satisfy claims of a third party arising from manually driven vehicles with low processual costs. This is reflected by average cost ratios of about $17.9 \%^{23}$ in the German motor insurance market. However, the efficiency of the current framework's claims process is mainly based on the fact that the owner of the vehicle and the driver are ultimately almost exclusively liable for third party losses caused by the usage of the insured vehicle. Therefore, the claimant directly contacts the respective motor insurance company as the institution, which also ultimately bears liability costs. Further litigation and subrogation claims ${ }^{24}$ are only rarely conducted by the motor insurer after the direct claim process of the damaged third party. ${ }^{25}$

However, the idea that the motor insurer is the central institution to claim and to absorb liability costs holds true for manually driven vehicles, where more than $90 \%$ of all accidents are caused by human error, but this could change for higher automated vehicles if product liability becomes more relevant. Hence, even where liability costs can adequately be allocated through subrogation claims of the motor insurance company after a single accident event, the owner of a vehicle maintaining MTPL insurance still has to pay for internal overhead-costs (eg claims-handling, execution of the subrogation claim) and safety margins for residual legal risk. These are accounted for in the motor insurance premium.

23 Source: German Insurance Association (GDV).

24 Today, subrogation claims in the motor insurance business are mainly relevant for cases where one of the insured parties breaches contractual obligations that have to be fulfilled before or after a loss occurrence.

25 C Schroll, "Splitting the Bill: Creating a National Car Insurance Fund to Pay for Accidents in Autonomous Vehicles" (2015) 109(3) Northwestern University Law Review 803 at 812. 
From a macro-level perspective of both the motor insurer and producer, the two-step approach of paying the claim of the damaged third party first and finally allocating liability costs by the way of subrogation claims potentially causes significant additional legal costs, which have to be absorbed by either the producer or motor insurance company. Ultimately, these costs are carried by the consumer either as the insured or purchaser of a car.

Hence, an unaltered preservation of the current framework could turn out as inefficient, at the latest with autonomous vehicles on the road. Therefore, simplifying the process of conducting subrogation claims for an MTPL insurer, for instance, with a refutable presumption of a product defect where a vehicle caused a crash in automated driving mode, would reverse the burden of proof to the manufacturer and could increase the efficiency of subrogation claims. This is because legal costs would only incur where OEMs can provide evidence that the accident was caused by the fault of the owner or human driver (eg inadequate maintenance, unintended use, etc). Consequently, only those accidents which are verifiably caused by the fault of the owner would be taken to court. As we assume that this will be the minor share of all accidents, legal and processual costs should be reduced.

In addition, we have described how a lack of insurers' ability or willingness could lead to an inadequate allocation of liability costs. This is the case if motor insurers, either due to a lack of technical and legal know-how or because of a lack of motivation, fail to prove the producer's liability where the conditions of producer's liability are actually fulfilled. Here, refutably presuming a product defect could also support liability costs being allocated based on the factual responsibility for loss causation in a specific loss event.

\section{Conclusion}

Our analysis of the appropriateness of the current insurance and liability framework shows that it largely ensures an adequate protection for third party claimants also for accidents caused by automated vehicles. Hence, this approach could generally be used as a blueprint for other jurisdictions, which base liability on the fault of the (human) driver. This, in turn, would also lead to a unification of different liability systems in the European Union and support the cross-border use of automated vehicles and, in particular, unify the legal requirements for the automotive supply side. Only minor adjustments, like the further increase of maximum liability amounts for owner's strict liability, are suggested to increase the level of claimant protection also for accident scenarios with extraordinary high cumulated loss amounts. With this approach, the general structure of the liability framework shown in Figure 1 would also be suitable for automated vehicles so that a damaged third party would be comprehensively protected with the existing possibility to claim directly against the motor insurer. ${ }^{26}$

Next to an adequate level of claimant protection, a central function of the liability and insurance framework is to allocate liability costs in a reasonable manner. In contrast to existing academic literature, we show that a reasonable and adequate allocation of liability costs is inhibited because of several barriers that hinder the shift of liability costs

\footnotetext{
26 With this approach, the procedure to directly claim against the producer shown with the broken line in Figure 1
} would not be required with automated vehicles on the road. 
from the owner of the vehicle to the manufacturer. We outline that this shift is highly dependent on the practical application of subrogation claims and show that the ability and the motivation of motor insurers to conduct subrogation claims is potentially negatively affected because of a lack of required technical and engineering know-how and an insufficient motivation to do so. This is because a market-wide conducting of subrogation claims would, in the long-term, erode the business of motor insurance. In addition, our in-depth analysis of specific provisions of the ProdHG also shows that exclusions and limitations of liability within this source of law potentially inhibit subrogation claims and thus a reasonable and adequate allocation of liability costs. In this case, the preservation of the current liability and insurance framework would inadequately conserve a predominant allocation of liability costs to the vehicle owner.

We show this circumstance as problematic because it not only impedes the incentive function for automotive manufacturers to maximise the inherent safety of their products but also allocates an unreasonable exposure of residual liability risk to the vehicle owner. Thus, we forecast that changes already made through the amendment to the StVG are not sufficient to meet the characteristics of automated driving vehicles. As outlined in our analysis, we propose revising the ProdHG to

(a) increase the limitation of liability for personal injury losses;

(b) set clear legal standards for testing and validation to support a consistent interpretation of the exclusion that the defect was not detectable with application of state-of-the-art methodologies;

(c) address the definition of the temporal attachment point of product circulation;

(d) address the threshold of $€ 500$ for product liability losses; and

(e) amend the requirement that the damaged item has to be ordinarily intended for private use or consumption.

However, we also see the point that the feasibility of proposed changes based on legal theory potentially conflict with the practical enforceable legal policy, which is influenced by the interests of single stakeholder groups. In particular, insurance companies are one of the major stakeholder groups regarding the allocation of liability for (automated) vehicles. Here, the future legal policy to allocate liability costs is a key variable determining the extent to which premium volume of traditional motor insurance premium could decrease or shift to product liability insurance. This could be one important strategic business-policy related reason why insurance companies call for a preservation of the current framework. ${ }^{27}$ Additionally, assuming that vehicle manufacturers generally rather avoid carrying financial risks resulting from accidents caused by their automated vehicles, a high consensus of interests would indeed exist between the motor insurer and the vehicle manufacturer.

\footnotetext{
27 German Insurance Association (GDV), "Stellungnahme des Gesamtverbandes der Deutschen Versicherungswirtschaft zum Entwurf eines Gesetzes zur Änderung des Straßenverkehrsgesetzes" <www.gdv.de/resource/blob/8810/ a724e876287fa4d229604fc385593dea/zum-gesetzentwurf-zum-automatisierten-fahren-2108997827-data.pdf > accessed 24 June 2018; BMW Group and Allianz Worldwide Partners, "Joint position on liability laws to be suitable for future automated vehicles" < www.allianz-partners.com/corporate/press-and-media/press-releases-and-news/BMW-Groupand-Allianz-Worldwide-Partners-Joint-position-on-liability-laws-to-be-suitable-for-future-automated-vehicles.aspx\#. WpqTPOcxmUk > accessed 24 June 2018.
} 
However, the consensus of interests also depends on the strategic approach of vehicle manufacturers of transforming their business model from a product-based sales approach and to a business model which is based on comprehensive mobility services. Some OEMs already claim that they are willing to bear liability costs which are due to accidents caused by their automated vehicles. ${ }^{28}$ This would imply carrying insurance risks on their own account. In addition, most of the OEMs are already actively involved in offering their own insurance solutions, either by own risk-carrying insurance entities inside the OEM groups or joint ventures and extended partnerships with traditional motor insurance companies. Here, the progressive connection and automation of motor vehicles could induce a broadening of this business activity and increase the competition to the traditional motor insurance market.

\footnotetext{
28 Volvo Car Group, "Volvo Cars CEO urges governments and car industry to share safety related traffic data" (2017) $<$ www.media.volvocars.com/global/en-gb/media/pressreleases/207164/volvo-cars-ceo-urges-governments-and-carindustry-to-share-safety-related-traffic-data > accessed 24 June 2018.
} 